\title{
Health and well-being promotion strategies for 'hard to reach' older people in England: a mapping exercise
}

\author{
Steve Iliffe ${ }^{1}$, Kate Walters ${ }^{1}$, Jill Manthorpe ${ }^{2}$, Claire Goodman ${ }^{3}$ and Kalpa Kharicha ${ }^{1}$ \\ ${ }^{1}$ Research Department of Primary Care \& Population Health, University College London, London, UK \\ ${ }^{2}$ Social Care Workforce Research Unit, Kings College London, London, UK \\ ${ }^{3}$ Centre for Research into Primary and Community Care, University of Hertfordshire, Hatfield, Hertfordshire, UK
}

\begin{abstract}
Background: Older people from deprived areas, the oldest old and those from ethnic minorities engage less in health promotion interventions and related research, potentially generating inequities. Aim: To explore and map the extent to which such 'hard to reach' groups of older people, are the focus of local health and well-being strategies in England. Methods: Document analysis of current health and well-being promotion strategies in a purposive sample of 10 localities in England with high proportions of some or all of the three hard to reach groups. Documents were analysed using an interpretive approach. Findings: A total of 254 documents were retrieved and reviewed. Much of the content of the documents was descriptive and reported the implications for resources/services of population ageing rather than actual initiatives. All localities had an Older People's Strategy. Strategies to counter deprivation included redistribution of winter fuel payments, income maximisation, debt reduction and social inclusion initiatives, a focus on older owner occupiers and recruitment of village 'agents' to counter rural deprivation. The needs of the oldest old were served by integrated services for older people, a community alarm service with total coverage of the $85+$ population, and dietary advice. The needs of black and minority ethnic (BME) older people were discussed in all localities and responses included community work with BME groups, attention to housing needs and monitoring of service use by BME older people. Three other themes that emerged were: use of telecare technologies; a challenge to the idea of 'hard to reach' groups; and outreach services to those at most risk. Conclusions: Document analysis revealed a range of policy statements that may indicate tailoring of policy and practice to local conditions, the salience of national priorities, some innovative local responses to policy challenges and even dissenting views that seek to redefine the policy problem.
\end{abstract}

Key words: deprivation; ethnicity; hard to reach; health promotion; older people; oldest old

Received 1 February 2017; revised 6 June 2017; accepted 12 June 2017; first published online 20 July 2017

\section{Background}

Increasing life expectancy has made healthy ageing a Public Health priority. Current policy in England

\footnotetext{
Correspondence to: Kalpa Kharicha, Research Department of Primary Care \& Population Health, University College London, Royal Free Campus, Rowland Hill St., London NW3 2PF, UK. Email: k.kharicha@ucl.ac.uk
}

(C) Cambridge University Press 2017
[Department of Health (DOH), 2010] emphasises tailored and person-centred approaches to prevention, partnership working across health and local government, and local solutions to promoting well-being (Oliver et al., 2014). Reducing inequalities is high on the policy agenda (Marmot, 2010; Bambra, 2016).

Multi-faceted interventions at different levels, tailored to specific settings and target groups seem 
likely to change behaviour (Grol and Grimshaw, 2003), improve general health perception and selfefficacy, and promote independent living in older people (Beswick et al., 2008). There is, however, limited evidence that such interventions work in the UK's National Health Service (NHS) (Frost et al., 2011), and clear signs that older people from particular groups engage less in health promotion (Liljas et al., 2017). Those who seem hardest to reach are the oldest old (aged $\geqslant 85$ years), people aged $\geqslant 65$ years from black and minority ethnic (BME) groups and people $\geqslant 65$ years living in deprived areas (Walters et al., 2017). This group have been described as those who are frail living in their own homes (Patmore, 2001), people with dementia and other mental health problems, those living in poverty, who do not speak English, who do not have friends or family and are socially isolated and those who do not know how or where to access services (Age UK, 2011).

This paper explores the extent to which 'hard to reach' groups of older people (sometimes called 'seldom heard' or 'easily forgotten') are the focus of preventative health service and local government initiatives in purposively selected areas of England. It was designed to inform a broader study exploring engagement with older people who are at risk of being marginalised from mainstream healthcare.

\section{Methods}

Our approach applied the methods of basic policy analysis outlined by Patton et al. (2015). Basic policy analysis is responsive to the policy problem it addresses, understanding that it may be difficult to define precisely - that is, the problem is 'fuzzy' or 'wicked'. We used the qualitative components of a policy analysis methodology developed in a previous study (Goodman et al., 2011) for the 'inventory' or 'search' phase of our analysis (Patton et al., 2015), This first phase is limited in scope and directed at a particular issue; health promotion policies designed to engage with hard to reach groups of older people.

Using categories derived from the literature review (Liljas et al., 2017), Age UK data was used to identify localities in England with the highest proportions of: (1) people aged 85 and over, (2) Ethnic minority communities or (3) those experiencing fuel poverty and/or claiming pension credit (as proxies for deprivation) among those aged 65 and over. These were then mapped onto five geographical regions of England (North of England, Midlands, East of England, London, and South/South West of England). A purposive sample of 10 localities was then selected including a spread of city/urban/rural areas. Table 1 shows their characteristics.

Health and well-being strategy documents for older people were identified for each area using local authority websites. Strategy documents from Health and Wellbeing Boards and NHS Clinical Commissioning Groups as well as Joint Strategic Needs Assessments (Cornes et al., 2008), served as starting points (see Box 1). These documents were reviewed to identify information on health and well-being strategies and plans, and/or any action taken with the three hard to reach groups that are the focus of this paper. In addition, related reports mentioned within or linked to these documents were found and reviewed. Data on the policies directed at hard to reach older people were summarised and extracted into an Excel sheet to facilitate analysis.

Table 1 Characteristics of study areas

\begin{tabular}{|c|c|}
\hline Code name & Characteristics \\
\hline Rural NE & $\begin{array}{l}\text { Overwhelmingly white British, dispersed } \\
\text { rural population, rural deprivation }\end{array}$ \\
\hline City SE 1 & High levels of fuel poverty \\
\hline $\begin{array}{l}\text { City } \\
\text { Midlands } 1\end{array}$ & $\begin{array}{l}\text { Amongst the most deprived local authority } \\
\text { areas in } 2010 \text {. High level of fuel poverty, } \\
\text { large ethnic minority community }\end{array}$ \\
\hline $\begin{array}{l}\text { Urban } \\
\text { South }\end{array}$ & $\begin{array}{l}\text { Coastal Town; one of the largest proportions } \\
\text { of oldest old people in England }\end{array}$ \\
\hline City NW & $\begin{array}{l}\text { Has proportionally high numbers of Irish, } \\
\text { Chinese, and Black African older people }\end{array}$ \\
\hline City SE 2 & $\begin{array}{l}\text { The most ethnically heterogeneous local } \\
\text { authority area in England, and also amongst } \\
\text { the top } 15 \% \text { most-deprived areas of England }\end{array}$ \\
\hline Rural NW & $\begin{array}{l}\text { Relative affluence masks significant pockets } \\
\text { of deprivation in one of the least densely } \\
\text { populated English counties. The ethnic } \\
\text { profile is changing to become more like the } \\
\text { rest of the UK with rapid increases in most } \\
\text { ethnic minority groups }\end{array}$ \\
\hline Rural SW & $\begin{array}{l}96 \% \text { of the older population is White British, } \\
\text { rapid growth of the oldest old age group }\end{array}$ \\
\hline $\begin{array}{l}\text { City } \\
\text { Midlands } 2\end{array}$ & $\begin{array}{l}\text { One third of } 65+\text { population receiving } \\
\text { pension credit }\end{array}$ \\
\hline Rural E & $\begin{array}{l}\text { Proportions of } 65+\text { and } 80+\text { higher than the } \\
\text { national average, with pockets of rural } \\
\text { deprivation }\end{array}$ \\
\hline
\end{tabular}




\section{Box 1 Data sources}

Health and Wellbeing Boards

The Health and Social Care Act 2012 established Health and Wellbeing Boards with the aims of working together to improve the health and well-being of local populations and reduce health inequalities.

Health and Wellbeing Boards comprise local authorities (public health, social care and children's services), NHS clinical commissioning groups (CCGs), and local Healthwatch (the consumer champion for health and social care).

Statutory guidance explains the duties and powers of Health and Wellbeing Boards' Joint Strategic Needs Assessments (JSNAs) and Joint Health and Wellbeing Strategies (JHWSs) (Department of Health, 2013).

The documents were analysed by three researchers using the three pre-determined categories of deprivation, oldest old and minority ethnic backgrounds, then re-analysed to identify other categories; differences of opinion were resolved through discussion. An interpretive approach was taken to document analysis, emphasising the way in which documents reveal their authors' interests, perspectives and presumptions (Murphy et al., 1998; Owen, 2014). According to Yanow (2007: 409): 'from an interpretive perspective the evidentiary material that the researcher analyses is constructed by participants in the event or setting being studied'.

\section{Findings}

A total of 254 documents with an explicit focus on older people were reviewed across the 10 localities. In some localities documents mentioning hard to reach groups also included homeless people and rough sleepers, the lesbian, gay, bisexual and transexual community, travellers, migrants, prisoners and those with drug dependence problems. This present paper discusses only the documented policies aimed at the oldest old, deprived older people, and older people from BME groups. The identified documents ranged from housing strategies and mental health strategies to overview public health reports, communications strategies and specific strategies targeting older people. The latter group of documents are summarised in Table 2. Documents were dated from 2009 to 2015 with some strategies having an operational end date up to 2020.

Although all localities had an Older People's Strategy (following the National Service Framework for Older People, DOH, 2001, and its successor NHS England, 2014), the overarching finding was the limited information about the promotion of health and well-being among the three hard to reach groups in these documents. Much of the content of the documents was descriptive of the local population, and reported implications for resources/services based on projections of population ageing. The development of specific strategies for various groups of older people, particularly those from BME groups (Manthorpe et al., 2008), followed a similar vein.

All localities framed their thinking in the context of limited resources in the public sector. For example, one Revised Partnership Strategy for Older People (2010-2013) described the context of its plans thus:

'It is not our intention to launch a stream of new initiatives but to co-ordinate what organisations are already doing and to build on current provision. Resources are limited and the challenge is to use these more creatively and effectively by working across boundaries and releasing more resources to service delivery. At the time of writing there is a range of newly emerging policies to consider. Therefore our outcomes need to be achieved within a changing environment'.

(City Midlands 2)

Despite this acknowledgement of limited resources, reducing inequalities has been a policy goal since the Marmot Review (Marmot, 2010) and was mentioned as a clear priority across the 10 localities.

\section{Deprivation}

A range of topics was grouped within the theme of deprivation, including fuel poverty, income maximisation, transport costs and accessibility of services. 
Table 2 Documents included in the review in addition to Joint Strategic Needs Assessments (JSNA) for Older People, Health and Wellbeing Strategies and Clinical Commissioning Strategies

\begin{tabular}{|c|c|}
\hline Code name & Documents reviewed \\
\hline ural NE & $\begin{array}{l}\text { Strategy Framework for Growing Older; } \\
\text { JSNA Dementia; JSNA Falls; JSNA End of } \\
\text { Life Care }\end{array}$ \\
\hline City SE 1 & $\begin{array}{l}\text { Older People's Housing Strategy; Older } \\
\text { People's Needs Assessment; Strategy for } \\
\text { Improving the Quality of Life of Older People }\end{array}$ \\
\hline $\begin{array}{l}\text { City } \\
\text { Midlands } 1\end{array}$ & $\begin{array}{l}\text { Joint Local Authority/CCG older peoples } \\
\text { strategy from the Health \& Wellbeing Board }\end{array}$ \\
\hline $\begin{array}{l}\text { Urban } \\
\text { South }\end{array}$ & $\begin{array}{l}\text { County Older People's Housing Plan; Older } \\
\text { People's Housing and Action Plan; Extra- } \\
\text { Care Housing Charging Strategy }\end{array}$ \\
\hline City NW & $\begin{array}{l}\text { Older People's Housing Strategy; JSNA End } \\
\text { of Life Care }\end{array}$ \\
\hline City SE 2 & $\begin{array}{l}\text { Older People's Health JSNA; Living Longer } \\
\text { Living Well: Regional Expression of Interest } \\
\text { for Health and Social Care Integration } \\
\text { 'Pioneer' Status }\end{array}$ \\
\hline Rural NW & $\begin{array}{l}\text { Promoting Health and Wellbeing for Older } \\
\text { People 2007-2016; Growing Older in County: } \\
\text { A report for the Director of Public Health and } \\
\text { the County Intelligence Observatory } \\
\text { Supporting County's Joint Strategic Needs } \\
\text { Assessment; Older People's } \\
\text { Accommodation and Wider Service Needs } \\
\text { Assessment 2010; Joint Older Persons' } \\
\text { Housing Strategy 2012-2017; Extra-care } \\
\text { housing strategy; End of life care strategy }\end{array}$ \\
\hline Rural SW & $\begin{array}{l}\text { Housing, Health, Care and Support Strategy } \\
\text { for Older People in County 2012-15; County } \\
\text { Dementia Strategy Priorities For 2013-2016 }\end{array}$ \\
\hline $\begin{array}{l}\text { City } \\
\text { Midlands } 2\end{array}$ & $\begin{array}{l}\text { Frail Older People Joint Strategic Needs } \\
\text { Assessment - Working Draft; Living Well in } \\
\text { Later Life Locality's Revised Partnership } \\
\text { Strategy for Older People 2010-2013; } \\
\text { Safeguarding Older People and Tackling } \\
\text { Isolation in locality Report of the Health \& } \\
\text { Older People Scrutiny Panel; Older People's } \\
\text { Mental Health And Dementia Including } \\
\text { Young Onset Dementia Strategy 2010-2015 }\end{array}$ \\
\hline Rural E & $\begin{array}{l}\text { Living Longer, Living Well The County's } \\
\text { Older People's Strategy Promoting } \\
\text { Independence and Wellbeing 2011-2014; } \\
\text { Health Needs Assessment Falls Prevention; } \\
\text { Joint Health and Wellbeing Strategy 2013/ } \\
\text { 14-implementation Investigate and report- } \\
\text { Carers of older people and people with long } \\
\text { term conditions; Dementia JSNA; Dementia } \\
\text { Access; The Mental Health Needs of Older } \\
\text { People in County } 2010 \text { Update; County } \\
\text { Council's Strong and Well Programme of } \\
\text { Support for Older People age 75+- } \\
\text { Priorities of the County's Older People's } \\
\text { Strategic Partnership }\end{array}$ \\
\hline
\end{tabular}

Fuel poverty, which disproportionately affects older people (Age UK, 2015), was recognised across localities. One locality (Rural East) had commissioned housing providers to provide energy advice and to deliver an outreach service for older people. Approaches such as increasing awareness of grants for improving energy use were widely reported. The not for profit sector was described as having a key role in addressing fuel poverty, one small initiative being its offer to act as a broker if some older people wanted to donate their ageentitled and non-means tested winter fuel payment to other older people in greater need.

One locality (City SE2) recognised that older people living in the most deprived parts of the locality and suffering from respiratory problems were likely to be most at risk of excess winter mortality. The policy response was to increase uptake of the influenza vaccine.

Its efforts to limit poverty more generally included:

'...putting efforts into income maximisation, eligibility for benefits, debt reduction and social inclusion initiatives among those who need it'.

(City SE2)

The costs and availability of transport were seen as potentially having an impact on the ability of older people with limited incomes to take up services in both rural (Rural E) and urban settings (City SE1) (where public transport for older people was free).

Urban deprivation may be more visible than the 'pockets of deprivation' in rural areas (Manthorpe and Livsey, 2009), where some proactive initiatives were described. One approach taken to address rural deprivation (Rural East) was working with Parish Councils to recruit village 'agents' who would signpost (mostly older) residents with unmet needs to services and community resources, and also promote volunteering. Other initiatives aimed at reducing fuel poverty were specifically targeted towards older people living in rural areas (e.g. Rural SW).

Limited access to services by older owner occupiers was recognised as a problem in one locality indicating another element of 'deprivation':

'Older people who live in social rented properties are more likely to be able access housing 
related support. This is not personal care but low level support that includes a daily check, help with form-filling and claiming benefits, supporting access to health services and promoting social inclusion etc. This support can often prevent higher level/acute interventions'.

(City SE1)

\section{The oldest old}

The impact of the growing numbers of the 'oldest old' on health and social care services was recognised in all localities, but in some places was perceived as a problem for the future. In some areas the 'oldest old' were acknowledged to already be an important population cohort; for example, in Rural SW there had been an increase of $15 \%$ in those aged 85 and older living with a long-term health condition between 2011 and 2015.

The most developed responses towards the oldest old in the 10 localities were found in Rural SW which aspired to more integrated services for older people at risk of losing their independence following an illness or hospital admission, with a focus throughout the system on regaining and promoting independence for as long as possible. The oldest old group was also considered in City SE1, which had been investigating hospital discharge of the oldest old with a view to reducing readmissions. While these approaches targeted the oldest old they addressed only the needs of those who had already come into contact with the health service.

In one locality particular problems affecting the over 85 s had been identified:

'...for the $85+$ population the commonest causes of admission are circulatory, injury \& poisoning and respiratory conditions. A lower proportion of cancer admission in this age group may be due to people with cancer not surviving until this later age. Admissions due to injury \& poisoning group are mainly emergency admissions, suggesting that (a) more robust falls prevention strategy could be required'.

(Urban South)
This same locality drew other conclusions from a public health analysis of hospital admission but framed these as managing complexity and not as a health promotion task:

'Looking at the types of conditions that form these co-morbidities we find that Injury \& Poisonings are more common as co-morbidities in the 85+ age group, whilst conditions relating to the digestive and musculoskeletal systems are more common as co-morbidities in the 65-84 year olds. This serves to highlight the different and complex care needs in the old and very old'.

(Urban South)

Urban South also noted the increased likelihood of malnourishment amongst people aged over 80 whilst Rural East reported plans, but not the details of cost-effectiveness, to promote a community alarm service aiming for total coverage of the $85+$ population in one locality.

\section{Ethnicity}

The theme of ethnicity provided the richest source of documented policy, covering the topics of population ageing, specific needs related to housing, understanding of needs that may be particularly relevant to minority groups, neglect of some problems (especially mental health), language, literacy and stigma, but also BME communities as sources of knowledge and support. Although much of this policy related to BME communities as a whole rather than older people, there has been a strong tradition in the UK of local strategies being constructed for BME older people (Manthorpe et al., 2008). The impact of the Equality Act (2010) has also promoted enquiry into ethnic inequalities and older people's services (Moriarty and Manthorpe, 2012). All localities aspired to improve engagement with ethnic minority groups.

In Rural NW, as in many areas, it was expected that:

'...over the coming years the county will be faced with changing demographics creating an older and more culturally diverse population.....and hence... an increased need to provide high quality personalised services'.

(Rural NW)

Primary Health Care Research \& Development 2017; 18: 563-573 
Rural NW had a vision for its citizens whereby they:

'...will have access to information and advice regarding how to identify and access options available within their communities to meet their cultural, health social care and support needs'.

(Rural NW)

This vision was framed as 'an 'asset-based' approach to empower communities to use the skills held within the community itself.

In City Midlands 1 the need for increased awareness of 'specific needs' was noted. It planned to develop an older person's strategy to support the coordination and delivery of culturally appropriate services covering health, social care, housing and other areas of relevance. The intention was expressed to improve access to information for older people from BME groups. One approach suggested was to encourage local professionals to explore ways improving two-way communication.

\section{Understanding needs}

One locality focussed on BME older people and dementia, drawing together two areas where there have been strategic and policy developments in England. It observed the:

'...lack of data related to risk factors and BME communities and with lack of such information it is difficult to understand the needs of these groups and target appropriate interventions that are tailored to their specific needs and involve them with current health promotion programs'.

\section{(Rural East)}

Addressing the mental health needs of older people in its area, a report from Rural East acknowledged that the mental health needs of BME communities had been particularly neglected. It observed that lack of awareness, stigma, language barriers and literacy problems were having an impact on this group. Cultural sensitivity of service providers was also mentioned as being needed. One recommendation was that:

'...commissioners and providers should ensure that current and future services are

Primary Health Care Research \& Development 2017; 18: 563-573 accessible to service users and carers of different ethnic groups'.

(Rural East)

City SE 2 noted an urgent need for improved language services for older people and had been reviewing the accessibility of main documents to those from BME communities. It noted that:

'on request, all documents can be translated into the most common languages and going forward [they] are looking into using local groups to help turn key documents into easy read versions'.

(City SE2)

The need for plain English and consistent, clear, simple communication had also been noted with recommendations that might apply to rural older people lacking IT access for a variety of reasons. The Communications and Engagement Strategy for Rural E stated that although:

'...seldom heard groups are less in Rural E than in other parts of the country (the CCG) will ensure that all external communications are inclusive and...take into consideration all barriers to access including language and access to computers'.

(Rural E)

With a view to making information more accessible to older people from BME communities City Midlands 2 had conducted an audit of adult social care and information about lifestyle. The appropriateness of the format of information was considered and possible additional approaches suggested, including prioritising word-of-mouth communication.

Working with community groups is a wellknown approach to engaging ethnic minority groups. In its review of preventing older people becoming isolated City Midlands 2 had visited BME community groups providing support to their older members. Such groups were acknowledged by City Midlands 2 local authority as a source of information, advice and guidance and moreover:

'...these groups were said to 'play a key role in preventing isolation of older people and 
preventing mental health conditions like depression and dementia'.

(City Midlands 2)

City SE 1's Forum for Older People was described as running a successful and innovative 'reaching out' programme of visits, which enabled peer-to-peer conversations between older residents to capture the views that need to inform commissioning arrangements. This Forum reported back regularly to the Older People's Partnership Board about their programme visits to local community organisations. In a local review of 'hard to reach' groups City SE 1 had solicited information from community groups including one making representations about older African People. One barrier was noted to be a 'lack of contact points across the partnership'. An initiative reported in City SE1 was the work of Community Nutrition Assistants providing advice on healthy eating to more than 800 older people in their own community languages.

A number of actions to address the strategic objective to 'Develop primary care, providers and commission services to enhance the quality of life for people with long term conditions' were outlined as part of City SE2's equality priorities. Amongst these was an intention to:

'Organise specific event for BME elders regarding Dementia awareness for themselves and carers'.

(City SE2)

\section{Accommodation}

There were some reports in the analysed documents that older BME people may not be aware of local housing-related support. While City NW had a lower proportion of the retirement age population from non-white minorities than the average for England, housing needs were included in consideration of this group by City NW. A housing scheme for Chinese older people was one example of BME specific retirement accommodation. The documents analysed described this scheme as working well because it employed Cantonesespeaking staff and had culturally specific facilities, however, it was also recognised that need for such schemes might decrease in the future as subsequent generations accommodated to British culture and learned English.
A proposal in Rural NW, in the context of older people's housing, for 'customer' profiling was put forward with a view to:

'...ensuring that the needs of minority groups are included in service planning'.

All City SE 1's extra-care provision (self-contained housing with care that can be purchased on site) of 140 units was described as being in one part of the locality. While the concentration of extracare provision in one area was reported to be consistent with the high number of local residents aged 65 years old and over living in that area, it was seen as directly disadvantaging the older BME population who lived predominately in the other part of the local authority and whose numbers were set to rise significantly over the next five years.

\section{Service use monitoring}

Equality data from providers and formal and informal feedback from patients and service users had provided City SE2 Clinical Commissioning Group (CCG) with details of user experience. In response to a service user suggestion that dementia service experience should be mapped against specific characteristics including age and ethnicity, the CCG reported it had:

'built more robust equality data collection into [a] new pathway as part of [an] incentive schemes for GPs' including "reviewing trends, access and outcomes". In addition there will be "an element of understanding the patient experience and this will be assessed by survey in various formats i.e. Day Centres, via the Dementia Café, within GP practices and for carers via on-line Survey Monkey"'.

(City SE2)

\section{Other themes}

Three other minor themes were identified in the strategy documents: the use of telecare technologies; a challenge to the idea of 'hard to reach' groups; and systems of outreach to those deemed to be at risk.

In Rural NE it was suggested that there:

'will be a large number of people, particularly older people who, although not known to 
Adult Services by their choice and/or not having high needs, who could still benefit from Telecare as a low level preventative service'.

\section{(Rural NE)}

A report on hard to reach groups in another area which had been commissioned by a local NHS Trust challenged dominant ideas about those who were seen as hard to reach/seldom heard/easily forgotten. It noted that the discussion of 'hard to reach' groups was confined to people who were pleased to hear from services rather than those who rejected such overtures, who were disengaged by choice and who displayed long-embedded resistance to professional 'intrusion'. It noted that 'outreach' work was one effective way to reach such individuals in terms of health promotion and prevention:

'What has become evident is that there is a community of professional and dedicated people working in the hard to reach sectors who have established effective models of practice and engagement with their communities in often emotionally difficult or potentially threatening and dangerous circumstances. It is safe to say that all of those contacted during the course of this project demonstrated a level of commitment and dedication to their roles and the communities they served that was highly effective and in many cases inspirational.

(Rural East)

This document indicated that the NHS and social services should instead consider support for older people who find it 'hard to access' services. It suggested that one improvement that is needed is the distribution of culturally appropriate, well-translated road maps of how to navigate health services and support for groups that would use this in their work with individuals. Similarly, in 2012 the CCG in Rural E planned a more proactive approach to identifying those older people at risk who rarely, if ever, had any contact with the health and social care services, but who presented at times of crisis, generally to acute hospitals.

Another scheme targeting specific older people who do not often access services (the 'difficult to reach') was a first contact service in City
Midlands 1, which offered advice on relevant services to older people in their own homes:

'it is designed to promote independence, wellbeing and where appropriate, active ageing by identifying people's needs and enabling access to services, particularly for those identified as "isolated" or "difficult to reach". The project offers a more coordinated and shared response which is more helpful and more caring than a number of ad-hoc visits and demonstrates true partnership working. It should ultimately reduce overall costs, but more importantly it has the potential to prevent accidents and promote independence and well-being.'

(City Midlands 1)

Similarly, an action plan for City SE2 sought to identify communities with specific health needs, including targeted engagement with 'seldom heard' people.

\section{Discussion}

\section{Summary}

The localities reviewed in this study adopted a broad approach consistent with a key message from the Marmot Review: 'Health inequalities result from social inequalities. Action on health inequalities requires action across all the social determinants of health' (Marmot, 2010). The hard to reach groups we chose to investigate featured in the policy documents in the 10 localities, but more in descriptive and aspirational accounts than in terms of practical interventions. Deprivation prompted the most practical efforts, around fuel poverty (a national priority), income maximisation and transport costs linked to service accessibility.

Those who were hard to reach amongst the oldest old were seen as a future problem in some localities and a current one in others, but ideas about how to address complex care needs were often vague. The limited policy commitment to integrated care in these localities matches the paucity of evidence about effective communitybased interventions (Frost et al., 2011). The policy about engaging with ethnicity as a factor inhibiting use of services, particularly health promotion, was far richer than that devoted to deprivation or the 
oldest old. Localities with few older people from BME communities anticipated the consequences of further demographic changes, whilst those with BME populations discussed in depth awareness of specific needs (like housing), the need to improve neglected aspects of NHS care like mental health services, and the challenges created by language difficulties, low levels of literacy and stigma.

Finally, document analysis revealed other crosscutting topics relevant to hard to reach groups, including telecare as a communication technique, and risk stratification at a population level for hard to reach individuals, followed by proactive outreach. Perhaps the most unexpected finding was the challenge, in one locality, to the idea of hard to reach groups as a category and its replacement by specific efforts to support older people who find it hard to access preventive services (Hernandez et al., 2010).

\section{Strengths and weaknesses of the study}

The strengths of this systematic documentary analysis are that it sampled across English regions to provide a contemporary 'snap shot' of current publicly available policy statements. On the practical level, however, there are often many hurdles to accessing evidence about policy, policy-making processes are often opaque, and obtaining relevant documents and papers can be problematic (Walt et al., 2008). The study's weaknesses are that it relied on public documents, and was unable to access internal documents (e.g. minutes of meetings) where much richer information may have been available about policy implementation; also, quantitative data was not scrutinised for its contribution to the policy analysis. Similarly, interviews with key policy figures might have been a useful methodological adjunct to further clarify the content and context of policy implementation. Our findings are not necessarily generalisable to other localities, but readers may note their applicability to their own situations, making them transferable.

\section{Comparison with the literature}

While there is a burgeoning literature on intervention-generated inequalities (Lorenc et al., 2013), relatively little empirical work has been done around intervention-generated inequity among older people. Previous studies (mostly from the
United States) around inequitable access to healthcare have focussed on less controversial domains such as gender, geography and socioeconomic status as researchers have often been uncertain how to handle inequities for older people. This study sheds light on how policy makers understand and approach hard to reach older people, who are likely to experience inequities in accessing and using services. Although populations and services differ greatly between countries, the methodologies that we have used (characterisation of hard to reach groups through literature review, developing an inventory of policies, qualitative analysis of the inventory examples) may be transferable to other jurisdictions and settings.

Social care research may have something to teach health services about ways of reaching marginalised groups. Engagement of 'hard to reach' through civil society organisations (religious organisations and faith groups, community groups, tenants/housing association groups, etc.) should be considered by service providers (Manthorpe et al., 2009), with the understanding that personal approaches may be more important for some ethnic minority communities than institutional approaches (McLean and Campbell, 2003).

\section{Implications for practice and research}

There is lack of conceptual clarity around the term 'hard to reach' and similar descriptions; 'isolated', 'hard to hear', 'seldom heard' or 'easily forgotten'. Clarification of the meanings of these terms would deepen our understanding of the 'hard to reach' phenomenon. The heterogeneity of policy documents may reflect genuine diversity between localities, but it could also be due to idiosyncrasies in the policy process at local level. It would be helpful to know which explanation is more common. We are left not knowing the impact of policies at local level as many providers working in communities do not collect data on 'protected characteristics' of the Equality Act (2010) (Moriarty and Manthorpe, 2012). This may reflect the priority given to conforming to plans rather than description of processes or measurement of outcomes. The creation of multiple strategies for different older people (BME groups, people with dementia, falls, and so on) makes it difficult to consider health promotion and prevention as cross-cutting themes but it may be an important task to join these up. 


\section{Conclusions}

Our findings suggest that those scrutinising local policy making and implementation will identify a broad range of documents. These are likely to reveal the heterogeneity of policy making, that in turn may indicate tailoring of policy and practice, the salience of national priorities (fuel poverty is our example but falls could be another), and some innovative responses to policy challenges. There may even be dissenting views that seek to redefine the problem addressed by policy. This high-level scrutiny does not allow judgements to be made about actual implementation efforts and their outcomes; this would require a deeper, mixedmethods approach in case studies (Walt et al., 2008) and linkages to other data about resource usage.

\section{Acknowledgements}

Bereni Oruitemeka carried out the document search and initial analyses for this paper.

\section{Authors' Contribution}

K.K. and S.I. reviewed the documents identified in the search, and all authors contributed to the analysis of the documents and the preparation of this paper.

\section{Funding Source}

NIHR/ SPCR FR8/218

\section{Conflicts of Interest}

The authors declare no conflicts of interest.

\section{References}

Age UK. 2011. Engaging with older people: evidence review. London: Age UK.

Age UK. 2015. Still cold: what next for older people in cold homes?. London: Age UK.

Bambra, C. 2016. Health divides: where you live can kill you. Bristol: Policy Press.

Beswick, A.D., Rees, K., Dieppe, P., Ayis, S., Gooberman-Hill, R., Horwood, J. and Ebrahim, S. 2008: Complex interventions to improve physical function and maintain independent living

Primary Health Care Research \& Development 2017; 18: 563-573 in elderly people: a systematic review and meta-analysis. Lancet 371, 725-35.

Cornes, M., Nagendran, T. and Manthorpe, J. 2008. Care and support needs in rural areas: a review of joint strategic needs assessments in England. London: King's College London.

Department of Health. 2001. National Service Framework for older people. London: Department of Health.

Department of Health. 2010. Equity and excellence: liberating the NHS. London: Department of Health.

Department of Health. 2013. Statutory guidance joint strategic needs assessments and joint health and wellbeing strategies. London: Department of Health.

Equality Act. 2010: The Stationery Office Limited, London. Retrieved 30 January 2017 from http://www.legislation.gov. uk/ukpga/2010/15/contents/enacted.

Frost, H., Haw, S. and Frank, J. 2011: Promoting health \& wellbeing in later life: interventions in primary care and community settings. Chief Scientist Office, Scottish Government. Retrieved 30 January 2017 from http://www.scphrp. ac.uk/promoting-health-wellbeing-in-later-life-interventionsin-primary-care-and-community-settings/.

Goodman, C., Drennan, V., Scheibl, F., Shah, D., Manthorpe, J., Gage, H and Iliffe, S. 2011: Models of inter professional working for older people living at home: a survey and review of the local strategies of English health and social care statutory organisations. BMC Health Services Research 11, 337.

Grol, R. and Grimshaw, J. 2003: From best evidence to best practice: effective implementation of change. Lancet 362 , 1225-230.

Hernandez, L., Robson, P. and Sampson, A. 2010: Towards integrated participation: Involving seldom heard users of social care services. British Journal of Social Work 40, 7.

Liljas, A.E.M., Jovicic, A., Kharicha, K., Iliffe, S., Manthorpe, J., Goodman, C. and Walters, K. 2017: Strategies to improve engagement of 'hard to reach' older people in health promotion interventions: a systematic review. BMC Public Health 17, 349.

Lorenc, T., Petticrew, M., Welch, V. and Tugwell, P. 2013: What types of interventions generate inequalities? Evidence from systematic reviews. J Epidemiol Community Health 67 , 190-93.

Manthorpe, J., Harris, J. and Lakey, S. 2008. Strategic Approaches for Older People from Black and Minority Ethnic Groups. London: Social Care Workforce Research Unit, King's College London.

Manthorpe, J., Iliffe, S., Moriarty, J., Cornes, M., Clough, R., Bright, $L$ and Rapaport, J, OPRSI (Older People Researching Social Issues) 2009: We are not blaming anyone, but if we don't know about amenities, we cannot seek them out': black and minority older people's views on the quality of local health and personal social services in England. Ageing \& Society 29, 93-113.

Manthorpe, J. and Livsey, L. 2009: European challenges in delivering social services in rural regions: a scoping review. European Journal of Social Work 12, 5-24. 
Marmot, M. 2010. Fair society, healthy lives: the Marmot review. London: Institute of Health Equity.

McLean, C. and Campbell, C. 2003: Locating research informants in a multi-ethnic community: ethnic identities, social networks and recruitment methods. Ethn Health 8, 41-61.

Moriarty, J and Manthorpe, J. 2012. Diversity in older people and access to services - an evidence review. London: Age UK.

Murphy, E., Dingwall, R., Greatbatch, D., Parker, S. and Watson, P. 1998: Qualitative research methods in health technology assessment: a review of the literature. Health Technology Assessment 2, 127-28.

NHS England. 2014. Safe, compassionate care for frail older people using an integrated care pathway: practical guidance for commissioners, providers and nursing, medical and allied health professional leaders. London: Department of Health.

Oliver, D., Foot, C. and Humphries, R. 2014. Making our health and social care systems fit for an ageing population. London: Kings Fund. Retrieved 30 January 2017 from http://www. kingsfund.org.uk/publications/making-our-health-and-caresystems-fit-ageing-population.
Owen, G.T. 2014: Qualitative methods in higher education policy analysis: using interviews and document analysis. The Qualitative Report 19, 1-19.

Patmore, C. 2001: Can managers research their own services? An experiment in consulting frail, older community care clients. Managing Community Care 9, 8-17.

Patton, C.V., Sawicki, D.S. and Clark, J. 2015: Basic methods of policy analysis and planning. Introduction, London, Routledge 3-5.

Walt, G., Shiffman, J., Schneider, H., Murray, S.F., Brugha, R. and Gilson, L. 2008: Doing' health policy analysis: methodological and conceptual reflections and challenges. Health Policy Plan 23, 308-17.

Walters, K., Kharicha, K., Goodman, C., Handley, M., Manthorpe, J., Cattan, M., Morris, S., Clarke, C.S., Round, J. and Iliffe, S. 2017: Promoting independence, health and well-being for older people: a feasibility study of computeraided health and social risk appraisal system in primary care. BMC Family Practice 18, 1.

Yanow, D. 2007: Qualitative-interpretive methods in policy research. In Fischer, F., Miller, G. and Sidney, M.S., editors Handbook of public policy analysis: theory, politics, and methods. Boca Raton, FL: CRC/Taylor \& Francis, 405-16. 